\title{
Evaluation of qualitative value for money of public-private partnership projects in Vietnam
}

\author{
Dinh Thi Thuy Hang \\ Nghe an College of Economics \\ Vietnam \\ hangngbia2001@yahoo.com
}

\begin{abstract}
It is expected that in the period of 2011-2020 projects under the model of public- private partnership (PPP) in Vietnam will continue to increase in both number and volume of financing. Despite the substantial volumes of the already performed investments, many practitioners in the field question the viability of Vietnamese PPP projects, in the road sector in particular. Enhancing the viability of these projects is, therefore, vital in the context of the ongoing economic growth. This research is proposing a qualitative value for money assessment, in order to examine the factors influencing PPP projects' viability in Vietnam. Employing the method of Structural Equation Modeling, the following two aspects will be included in the analysis: 1) financial performance \& economic environment; 2) technical capacity \& legal environment. The former encompasses "financial interest", "profitability", "economic policy" and "demand of service"; while the latter covers "service quality", "flexibility of contracts", "legal framework" and "statutory compliance".
\end{abstract}

Received:

April, 2017

Keywords: Public-private partnership (PPP), road sector, viability, Value for Money (VFM), Structural Equation Modeling (SEM).

\section{JEL Classification: L32, L33}

\section{INTRODUCTION}

For two decades by now, public-private partnership has been considered as an irreplaceable alternative to more traditional approaches of procurement in the public roads sector in many countries. This trend is evidenced by the use of the PPP approach in implementation of 958 road infrastructure projects that are worth about USD274.025 million and have been finalized within 1990-2015 (World Bank, 2017). One of the main objectives of PPP is to transfer the development of infrastructure to the private sector, in order to achieve efficiency, cost viability and financial performance (Alfen et al., 2009). Besides letting the private sector implement a public-sector project that may also involve partial public funding, PPP also involves the provision of services by private investors and the transfer of many risks from public to private sector (International Monetary Fund, 2006). In general, most studies have argued 
that the benefits the policymakers derive from a PPP model include: cost-saving, risk allocation, improvements in quality of public services, and the utilization of private sector skills and expertise. Having stated that, it is necessary to clarify what is meant by the term PPP as such. While there is a multitude of concepts of PPP, one of the most common definitions was given by the Asian Development Bank (2008), according to which PPP is "a range of possible relationships among public and private entities in the context of infrastructure and other services".

The concept of PPP is not new for Vietnam, with the first Build Operate Transfer (BOT) projects tracing back to the late 1990s. Since Vietnamese Government enacted the BOT law in the early 1990s with the aim of attracting private investments into road projects development, there have been more than 62 PPP projects in the country's road sector, with the overall investments totaling around VND 186,660 bln (Vietnamese Ministry of Transport, 2016). However, such quantity is certainly not an indicator of quality, as some of those 62 projects are now deemed as failures. This is because shortly after the first days of operation, the concessionaires simply did not have sufficient capital to carry out projects, so they decided to return them back to the public sector. Stakeholders in the field have found that the viability of Vietnamese PPP road projects has not been appropriately recognized. The central issue remains open: how to improve the viability of PPP in road sector in Vietnam? This is also the core question behind this research. In order to answer it, the research adopts a qualitative value for money (VFM) assessment. With the aim of acquiring data for implementation of this research, the survey was administered among Vietnamese BOT/PPP stakeholders, comprising governments' officers, financiers, engineers and insurers, contractors etc., directly involved in ВОT/PPP projects.

It should be noted that many researchers have conducted qualitative VFM assessments to explore the elements that affect the success of PPP, however, not many of them have focused on quantifying the effects from influence factors on the viability of PPP. This research is one of a few studies that provide a quantitative approach using the method of Structural Equation Modeling in a qualitative VFM study to measure the influence of factors on PPP's viability.

This paper begins with the literature review concerning qualitative VFM, covering also definitions and evaluation factors. Then, this paper presents the methodology to be employed. The third section outlines the results and findings. Finally, a brief discussion and implications from this research are provided. The shortcomings of this research as well as suggestions for future work in the same direction are closing this article.

\section{LITERATURE REVIEW}

\subsection{Definition of qualitative value for money assessment}

The HM Treasury (2006) defines that qualitative VFM as a process of analysing "factors, like a service' quality, which are not easy to quantify (HM Treasury, 2006, p.7). This definition reflects the views in Morallos and Amekudzi (2008) that "unlike the quantitative assessment, the qualitative assessment is often less prescriptive, it will often vary by what the procuring agency deems important to consider, depending on the project and other conditions" (Morallos \& Amekudzi, 2008, p.115).In Government of India (2010), a qualitative VFM tests "for qualitative factors that have an impact on the ease or difficulty of doing the project as a PPP" (Government of India, 2010, p.11). According to the National Audit Office (2013) "the qualitative assessment, unlike the quantitative assessment, does not require project teams to compare PFI to the public sector comparator. Instead, all the questions in the qualitative assessment are focused on whether or not PFI will meet the intended outcomes of the project" (National Audit Office, 2013, p.11). 
Hence, although there are varying perspectives in the literature, most views agree that qualitative VFM can be seen as a process that facilitates the evaluation of the impacts of qualitative factors on the viability of PPP.

\subsection{Determination of factors for qualitative VFM assessment}

In order to apprise the qualitative VFM of a PPP project, the commonly VFM guidelines identifies certain criteria that are based on different aspects. In the guideline for value-for-money test specified in United Kingdom (2006), the computation of the qualitative elements is based on 39 questions. These questions are designed to capture three dimensions - viability, desirability and achievability. In detail, these aspects are associated with the value of the project, the technology, the allocation of risks and incentives, the government's economic policy, the existence of a favorable legal framework, and the flexibility of contracts to changes in output. Likewise, according to the detailed guideline for value for money test in Korea (2010), qualitative criteria was divided into four main components, including the suitability of a PPP, efficiency in project's implementation, the easiness of the project's implementation, and the effects of risk sharing. These aspects are related to a set of 14 items that consists of the level of services, competition, improvements in technology, improvements in management skill, the project's conformity to national policy, the consumers' capacity, the interests of every party involved, the operation independent of projects and the easiness of the execution of the contracts.

In addition to government documents regarding PPP guidelines, empirical researches also identified criteria for qualitative VFM assessment in PPP projects. For example, a study by Ozdogan and Birgonul (2000) identified four different approaches for assessment of BOT/PPP project viability, such as financial and commercial factors, political and legal factors, and technical factors and social factors. These approaches are further classified into 37 factors, such as the experience of the government, the political environment, the project's size, the economic environment, the ability to attract foreign investors, and the legal framework. Additionally, having conducted a survey to explore the views of PPP experts in 13 countries, Zhang's (2006) researchargues that the four characteristics that can create the best value for the public in PPP infrastructure projects center on enhancement of infrastructure development, improvements in the construction and management process, the cost effectiveness of the project's procurement, and the promotion of the development priorities. These are associated with 21 elements, such as such as risk transfer, technical innovation, low cost, improved construction and maintenance, optimized resources utilization, and long project life cycle. Furthermore, Zhang (2005) also suggests that the aspects needed to evaluate the feasibility of PPP projects, should include financial considerations technical considerations, safety and health concerns, and a close look at the environmental and managerial aspects of a project.

Apart from these research findings, there are also many other studies identifying main factors which contribute to viability of PPP. As an example, based on comprehensive review of 50 previous studies, Thomas et al. (2010)and Wong (2006) developed 36 evaluation criteria for determining the feasibility of PPP projects. These factors are classified into the following groups - financial \& economic factors, technical factors, social factors, political and legal factors, and others. Similarly, based on 27 publications between 1990 and 2013, Kyei and Chan (2015) also researched on the possible factors that affect a PPP. In comparison however, the list in Thomas et al. (2010) and Wong (2006) seem to be more comprehensive. 
Summarized list of evaluation factors for viability study of PPP

\begin{tabular}{|c|c|}
\hline Code & Evaluation factors \\
\hline \multicolumn{2}{|c|}{ Financial performance \& economic environment } \\
\hline F1 & Project is more cost effective than traditional forms of project delivery \\
\hline F2 & Project can be substantially self-funded \\
\hline F3 & Project value is sufficiently large to avoid procurement disproportionate procurement costs \\
\hline F4 & Project is of financial interest to private sector \\
\hline F5 & Project can attract foreign capital \\
\hline F6 & Project is bankable and profitability of the project is sufficient to attract investors and lenders \\
\hline F7 & Economic environment is stable and favorable \\
\hline F8 & Existence of a sound governmental economic policy \\
\hline F9 & Competition from other projects is limited \\
\hline F10 & There is a long-term demand of the products/service in the community \\
\hline F11 & Level of toll/tariff is acceptable \\
\hline \multicolumn{2}{|c|}{ Technical sophistication } \\
\hline F12 & Project size is technically managerial by a single consortium \\
\hline F13 & Possibility of innovative solutions \\
\hline F14 & Availability of government experience in packaging similar PPP projects \\
\hline F15 & Available of experienced, strong and reliable private consortium \\
\hline F16 & Service quality can be easily defined and objectively measured \\
\hline F17 & Contract is flexible enough for frequent change in output specification \\
\hline \multicolumn{2}{|c|}{ Social system } \\
\hline F18 & The community is understanding and supportive \\
\hline F19 & Project can create more job opportunities \\
\hline F20 & Project is environmentally sustainable \\
\hline \multicolumn{2}{|c|}{ Political and legal environment } \\
\hline F21 & Project is not political sensitive \\
\hline F22 & Political environment is stable \\
\hline F23 & There is political support for the project \\
\hline F24 & The project is compatible with current statutory and institutional arrangements \\
\hline F25 & There is a favorable legal framework \\
\hline \multicolumn{2}{|c|}{ Managerial capacity } \\
\hline F26 & Fairness of new conditions to employees \\
\hline F27 & Possibility of significant redundancy \\
\hline F28 & Supportiveness and commitment of staff to the project \\
\hline F29 & Existence of a resolution for any civil service staff redundancy \\
\hline F30 & Flexibility do decide appropriate risk allocation \\
\hline F31 & Support from the Government is available \\
\hline F32 & Authority can be shared between public and private sector \\
\hline F33 & Possibility of an effective control mechanism over the private consortium \\
\hline F34 & Matching governments strategic and long-term objectives \\
\hline
\end{tabular}

Source: Thomas et al. 2010 


\section{METHODOLOGY}

This research applied qualitative VFM assessment using the method of Structural Equation Modeling (SEM) to assess the effects of factors on viability of PPP in road sector. The SEM method is more advisable for the following three reasons: Firstly it allows us to evaluate hypothesized models regarding relationships among observed and unobserved variables, secondly it allows us to test theoretical model quantitatively given practical evidence, and finally it helps provide a best fit model associated with relationships among variables.

In order to conduct the qualitative assessment of PPP projects in general, 34 factors were adopted from Thomas et al. (2010). These are further summarized in Table 1. According to Cheung and Chan (2011), "there is no strong justification to reinvent work that has previously been discovered by other researchers" (Cheung \& Chan, 2011, p. 60). Cheung (2009) also argues that utilizing the same instrument would allow future research to be compared with the earlier one in terms of the same factors that apply to PPPs in different countries.

The structural equation model (SEM) used throughout this research was designed for five exogenous variables and one endogenous variable (see Figure 1). The details of these variables are summarized as follows.

(1) The exogenous variable captures the extent of financial performance and the economic environment were computed from the observations associated with the entries in F1 through to F11.

(2) The exogenous variable that captures the level of technical sophistication was computed from the observations associated with the entries in F12 through to F17.

(3) The exogenous variables representing the social system was measured by observations associated with variables F18 to F20.

(4) The exogenous variable representing the political and legal environment was measured from observations associated with variables F21 to F25.

(5) The exogenous variable that captures the other issues was computed from the observations associated with variables F26 to F34.

(6) The latent variables that capture the nature of a PPP projects' viability were estimated through a survey on the how satisfied the respondents are with the feasibility of a PPP projects in the construction stage (V1) and in operation stage (V2).

Structural model describes the effects of factors on the PPP'viability with five hypotheses, including:

H1: Financial performance and economic environment have a positive impact on the viability of PPP

H2: Technical sophistication positively influences the viability of PPP

H3: Social system positively contributes to the viability of PPP

H4: Political and legal environment positively contribute to the viability of PPP

H5: Managerial capacity positively impacts the viability of PPP 


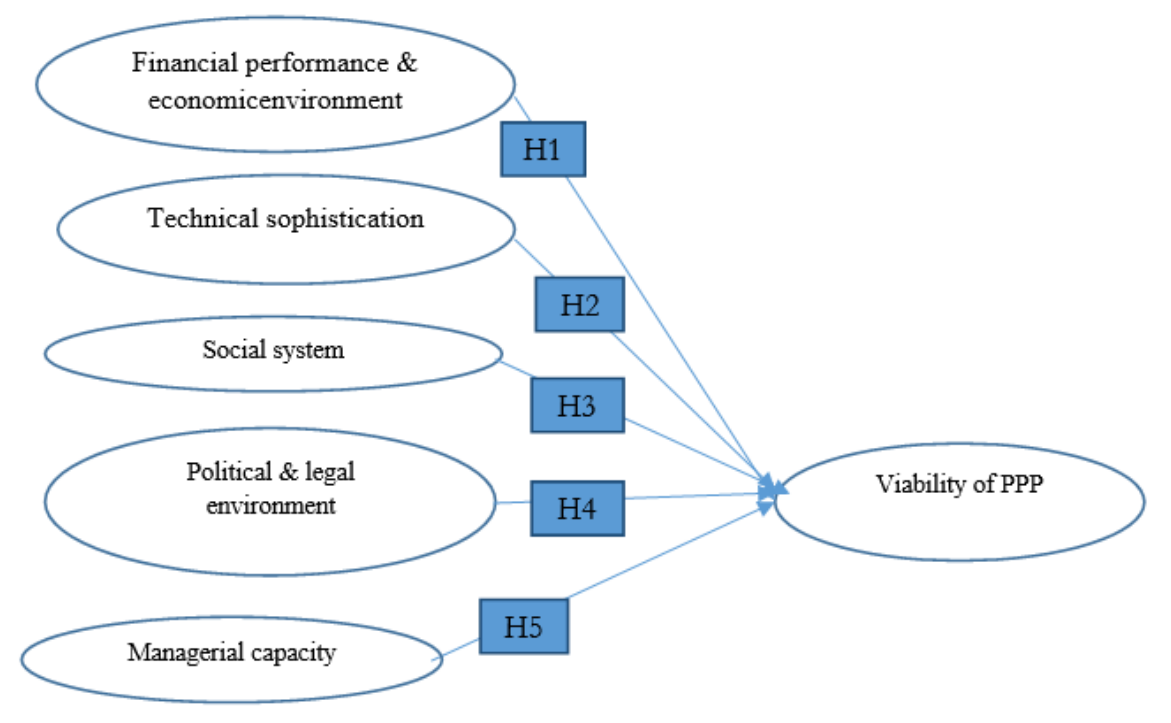

Figure 1. Hypothesized structural equation model to measure effects of factors on the viability of PPP

\section{EMPIRICAL RESULTS AND DISCUSSION}

\subsection{Empirical results}

\section{Characteristics of respondents}

The survey investigating perspectives of BOT/PPP stakeholders in Vietnam was implemented between March and April in 2016. Through the snowball sampling, a total of 300 questionnaires were distributed to respondents, among which 210 responses were received, achieving a 70\% response rate. However, nine responses were not fully completed. In order to ensure that the assessment is reliable, the nine odd questionnaires were removed. As a result, the remaining 201 responses were used to be analyzed for the research, correspondent to $66.7 \%$ of the total sample. As can be seen in the table 2 , there were 141 participants with less than 15-year working experience, making up slightly more than 70 percent of the total. Whereas the other 60 respondents had more than 15-year working experience, making up roughly 30 percent. Approximately 13 percent of participants had worked in more than five BOT/PPP projects, while about 30 percent of them had taken part in one BOT/PPP project. The number of respondents from public sector is 53, representing 26.4 percent, while the figure from private sector is 148 , accounting for 73.6 percent. 
Characteristics of respondents

\begin{tabular}{|l|c|c|}
\hline \multicolumn{1}{|c|}{ Characteristic } & Frequency & Percentage (\%) \\
\hline Experience years & & $70.2 \%$ \\
\hline Less than 15 years & 141 & $29.8 \%$ \\
\hline More than 15 years & 60 & $22.9 \%$ \\
\hline Number of BOT/PPP projects & & $26.4 \%$ \\
\hline 1 & 46 & $18.9 \%$ \\
\hline 2 & 53 & $11.9 \%$ \\
\hline 3 & 38 & $7 \%$ \\
\hline 4 & 24 & $12.9 \%$ \\
\hline 5 & 14 & $26.4 \%$ \\
\hline Above 5 & 26 & $73.6 \%$ \\
\hline Sector & & \\
\hline Public & 53 & \\
\hline Private & 148 & \\
\hline
\end{tabular}

Source: Synthesized by author

\section{Explanatory factor analysis}

With the aim of examining whether the collected data is fit for factor analysis, KMO and Bartlett's Test of sphericity test were implemented. The results reveal that Bartlett's Test of sphericity was 2080.152, significant level was 0.000 and $\mathrm{KMO}$ of 0.854 (table 3). This is in line with the suggestion of Hair, et al (2010), a KMO value from 0.8 to 0.9 is good. The significant level of Bartlett's Test of sphericity was $0.000(<0.05)$ confirmed that the survey data was very suitable for factor analysis, and the relationship among factors was rather good. After a reliability test and two factor rotation tests, 14 factors were eliminated out of the model, including F11, F12, F19, F23, F15, F13, F21, F14, F2, F33, F31, F30, F32 and F34.

After rotating components (see Appendix Table 1), there were three components interpreted as the following three dimensions:

Group 1 combines "fairness of new conditions to employees", "resolution for staff redundancy", "significant redundancy", "supportiveness of staff to the project", "stable political environment", "governmental economic policy", "environmental sustainability", "Competition from other projects is limited", "supportive community", and "effective cost", which is correlated to managerial capacity, accounting for $32.93 \%$ of the total variance.

Group 2 comprises "financial interest to private sector", "attraction of foreign capital", "sufficient project value", "profitability of projects", "stable economic environment", and "demand of service" which is associated with financial performance and economic environment, accounting for $16.15 \%$ of the total variance.

Group 3 includes "service quality", "flexible contract for change in output", "favorable legal framework" and "align with current statutory", which is related to technical sophistication and legal environment, making up $9.03 \%$ of the total variance.

\section{Structural equation model analysis}

\section{Initial SEM model}

Three factor groups achieving from explanatory factor analysis were given to the SEM analysis in order to investigate the effects of factors on the viability of PPP projects. An initial SEM model is 
presented in Figure 2. The initial model comprised of three exogenous constructs and one endogenous. Exogenous included managerial capacity, financial performance \& economic environment, and technical sophistication\& legal environment; and one endogenous was the viability of PPP. A total of 22 observed variables were utilized to compute these four constructs.

In order to determine the best-fit model of relationships between evaluation factors and the PPP' viability, the Statistical Package for the Social Sciences software (SPSS) 20 and Amos 22 were utilized in the research. Some fit indices were used to evaluate the suitability of the alternative models, namely the minimum fit function chi-square $(\chi 2)$ ratio degree of freedom test, the root mean square error of approximation (RMSEA), the comparative fit index (CFI), Tucker-Lewis Index (TLI) and goodness-of-fit index (GFI).

Table 3 confirms the fit indices of the initial model, revealing a CMIN/DF value was 3.21. According to Hooper D et al. (2008), value of CMIN/DF is from 2 to 5, suggesting a hypothetical model is accepted fit. In addition, the value of CFI was 0.793, which was lower compare to the accepted level of 0.9 suggested by $\mathrm{Hu} \&$ Bentler (1999). Likewise, the value of GFI was 0.78, which did not achieve the threshold of 0.9recommended by Byrne (2010). The RMSEA had a value of 0.10, which was larger than the advised levels of 0.5 to 0.8 by Browne \& Cudeck, (1993). Together with the TLI value of $0.76(<0.9)$, the result implies that the model fits poorly. On the other hand, table 4 illustrates regression weights of structural equation model analysis, confirming that the relationship between managerial package and the PPP's viability is not statistically significant ( $\mathrm{p}$-value of managerial capacity $<0.05$ ). In other words, managerial capacity had little to no impact on the PPP's viability.

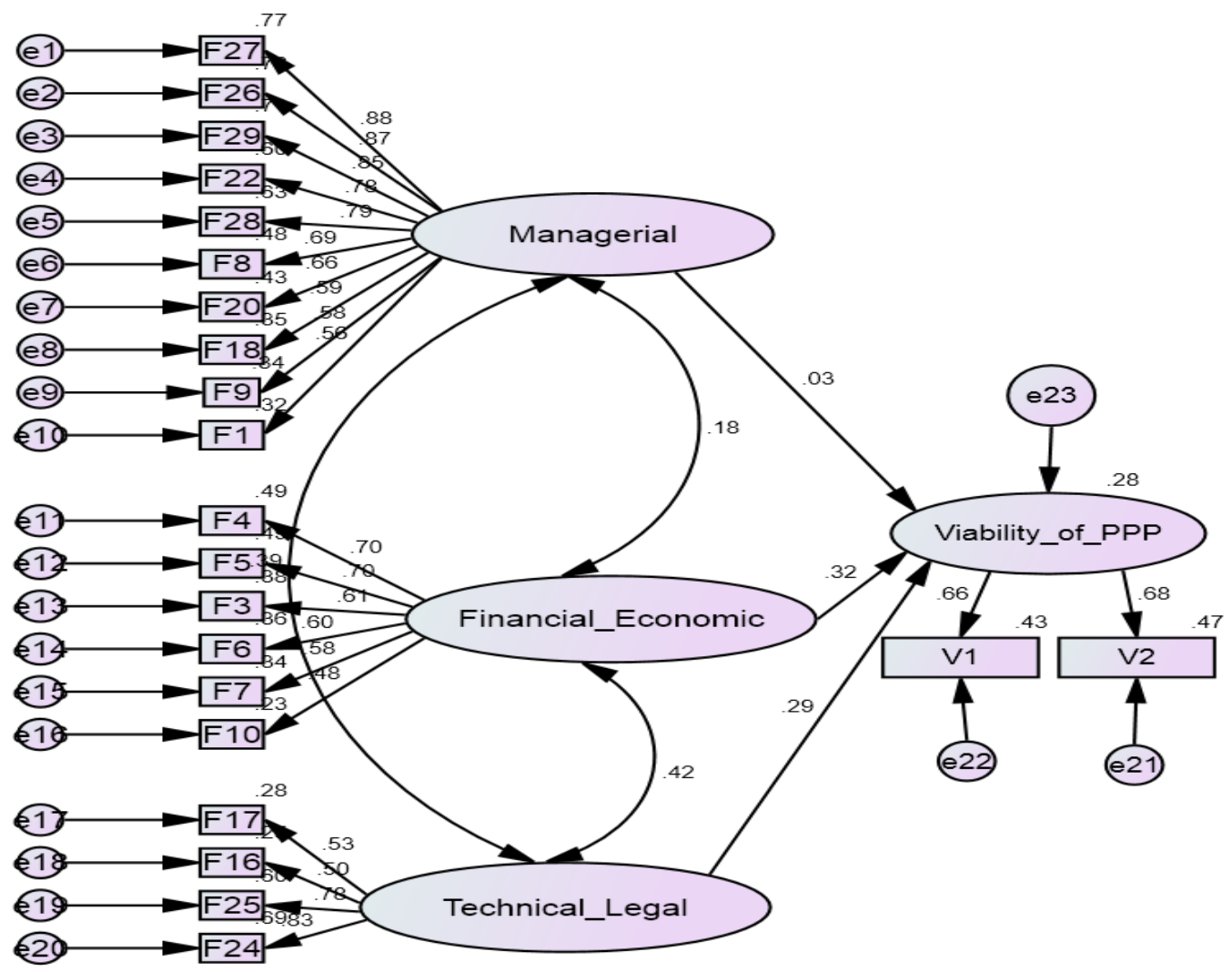

Figure 2. Correlation coefficient of initial structural equation model Source: Author's result 
Table 3

Fit indices for the alternative structural equation model

\begin{tabular}{|l|c|c|c|c|c|}
\hline \multicolumn{1}{|c|}{ Indices } & $\begin{array}{c}\text { Good model } \\
\text { fit }\end{array}$ & $\begin{array}{c}\text { Accepted } \\
\text { model fit }\end{array}$ & References & $\begin{array}{c}\text { Initial } \\
\text { model }\end{array}$ & $\begin{array}{c}\text { Final } \\
\text { model }\end{array}$ \\
\hline CMIN/DF & Value $<2$ & $<5$ & Hooper, D et., al (2008) & 3.21 & 1.74 \\
\hline RMSEA & Values $<0.05$ & $<0.08$ & $\begin{array}{c}\text { Browne \& Cudeck, } \\
(1993)\end{array}$ & 0.10 & 0.06 \\
\hline CFI & Values $>0.95$ & $>0.90$ & Hu \& Bentler (1999) & 0.79 & 0.95 \\
\hline TLI & Values $>0.95$ & $>0.90$ & $\begin{array}{c}\text { J.J. Hox \& T.M. } \\
\text { Bechger (1998) }\end{array}$ & 0.76 & 0.93 \\
\hline GFI & & & Byrne (2010) & 0.78 & 0.94 \\
\hline
\end{tabular}

Table 4

Exploring alternative structural equation models

\begin{tabular}{|c|c|c|c|c|}
\hline Model & Relations & Estimate & $\mathbf{P}$ & Significant \\
\hline \multirow{3}{*}{$\begin{array}{l}\text { Initial } \\
\text { model }\end{array}$} & H5: Managerial $\longrightarrow$ viability of PPP & 0.03 & 0.716 & No \\
\hline & H1: Financial \& economic $\longrightarrow$ viability of PPP & 0.32 & 0.005 & Yes \\
\hline & H2,H3: Technical and legal $\longrightarrow$ viability of PPP & 0.29 & 0.020 & Yes \\
\hline \multirow{2}{*}{$\begin{array}{l}\text { Final } \\
\text { model }\end{array}$} & H1: Financial \& economic $\longrightarrow$ viability of PPP & 0.34 & 0.003 & Yes \\
\hline & H2,H3: Technical and legal $\longrightarrow$ viability of PPP & 0.31 & 0.008 & Yes \\
\hline
\end{tabular}

Source: Author's result

Final SEM model

With the aim of achieving the best-fit model, the managerial capacity was removed from the initial model. The fit indices of new model seem to be better than in the initial model. For example, the value of CMIN/DF was 1.79, which is very good compared to the standard (close to 2). Likewise, the new CFI value of 0.93 ; TLI value of 0.91 and GFI value of 0.92 , were relatively high given the desired level. In addition, RMSEA was 0.06, which seems to be good given the suggestion of Browne \& Cudeck (1993). It suggests a reasonable model fit. However, in the new model, factor F10 had a factor loading of 0.48 . According the suggestion of Hair et al (2010), one should remove factor loading of less than 0.5. Therefore, factor F10 was eliminated in the model. In addition, the error items 14 and 15, which had larger value of modification index, should be linked together in order to obtain the optimal model (Table 5). Figure 4 describes the path diagram of final model after removing managerial capacity and factor F10 from the initial model; at the same time adding the relationship between error items 14 and 15.Again from the table 3, the fit indices in the modified model improved to achieve the desired threshold of good model fit, especially in terms of CMIN/DF $=1.74<2$, RMSEA $=0.06<0.08$; CFI $=0.95>0.90$; TLI $=$ $0.93>0.90$; and $\mathrm{GFI}=0.94>0.9$. 


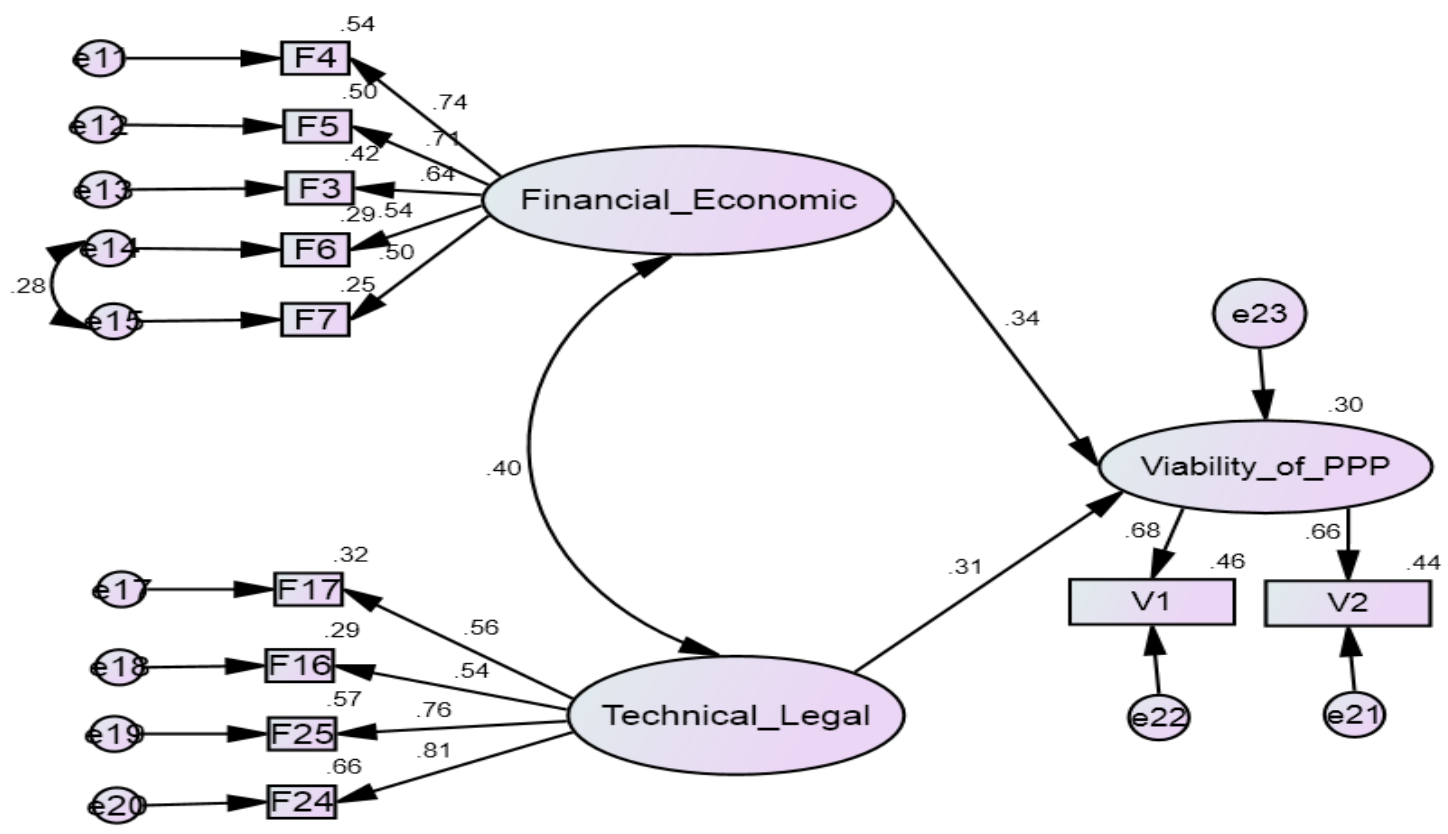

Figure 3.Correlation coefficient of final structural equation model

Source: Author's result

Table 5

Modification Index of model

\begin{tabular}{|c|c|c|c|c|c|}
\hline Model & error term & & error term & M.I & Par change \\
\hline & 14 & $\longleftrightarrow$ & 15 & 11.55 & 0.17 \\
\hline
\end{tabular}

Source: Author's result

\section{Analysis of path diagram in final SEM model}

The findings of path analysis indicate that financial \& economic and technical \& legal packages significantly affect the suitability of PPP at p-value of less than 0.05 (see Table 4). The two latent factors explained 30 percent of the total variance of the value for money. It also means that hypothesis $\mathrm{H} 1$ and hypothesis $\mathrm{H} 2, \mathrm{H} 3$ are accepted, while hypothesis $\mathrm{H} 4$ and $\mathrm{H} 5$ are rejected. As can be seen in Figure 3, the direct effect of financial performance \& economic environment on value for money was computed by the regression weight 0.34 and the direct effect of technical sophistication\& legal environment on value for money was calculated by the regression weight 0.31 . The interrelationship between financial performance \& economic environment and technical sophistication\& legal environment was measured by correlation coefficient 0.40 . The indirect effect of financial performance \& economic environment on the viability of PPP via technical sophistication\& legal environment can be computed as $0.40 * 0.31=0.12$, which plus the direct effect created a total effect of 0.46 . Likewise, the indirect effect of technical sophistication\& legal environment on viability of PPP through financial performance \& economic environment can be measured as $0.40 * 0.34=0.14$, which in combination with the direct effect, lead to a total effect of 0.45 . The sizes of these values demonstrate that financial performance \& economic environment have bigger impact on PPP projects' viability than technical sophistication\& legal environment.

Multiple group analysis was applied to evaluate whether respondents' working sector, including public sector and private sector, impact on the relationships in the SEM model. Firstly, we constructed an 
unconstrained model for groups of public sector and private sector. Secondly, we also computed the constrained model, in which the parameters were limited in order to be equal for both groups. Lastly, we tested the difference between chi-square of the unconstrained and constrained model. If chi-square difference test is not significant, the implication is that there is an agreement between the unconstrained and constrained model. In contrast, if chi-square difference test is significant, it can be said that there is a disagreement between the two models. In this research, the results of chi-square difference of 24.012 with 10 degree of freedom and a p-value of $0.0075(<0.05)$ reveals that there is disagreement between the unconstrained and constrained model. This means the multiple groups in unconstrained model can be used. Specially, unconstrained model for public sector is described in figure 4, while unconstrained model for private sector is illustrated in figure 5. Regarding public sector, the direct effect of financial performance \& economic environment on the PPP viability of projects was 0.16 and total effect was 0.38 , while direct effect of technical sophistication\& legal environment was 0.69 and total effect was 0.74 . For private sector, the direct effect of financial performance \& economic environment on the viability of PPP was 0.4 and total effect was 0.47 , while indirect effect of technical sophistication\& legal environment equal 0.20 and total effect was 0.30 . This implies that for public sector, technical sophistication\& legal environment are more important than financial performance \& economic environment to improve the PPP viability. In contrast, for private sector, financial performance \& economic environment are important than technical sophistication\& legal environment to enhance the viability of PPP. Thus, it can be concluded that working sector of the respondents can significantly influence the relationships in the SEM model.

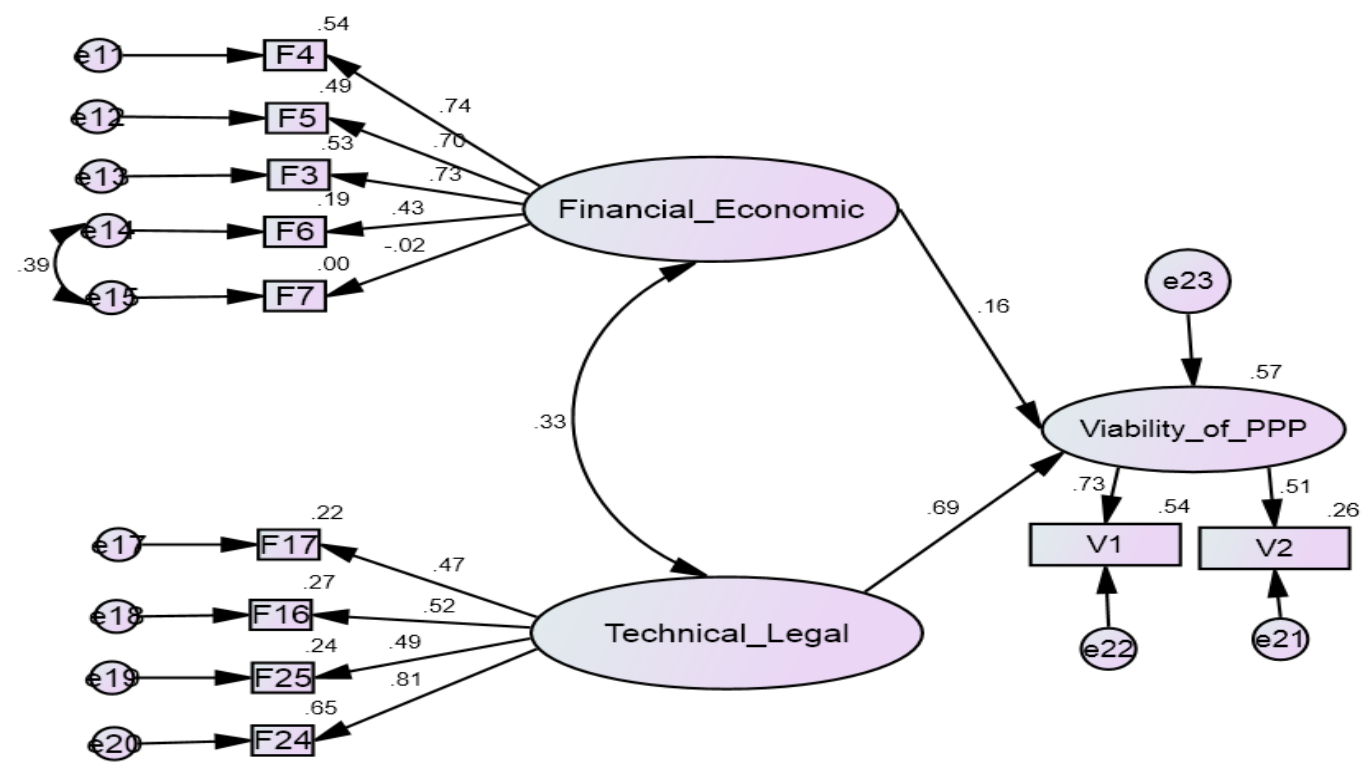

Figure 4. Standardized SEM model for Public sector

Source: Author's result 


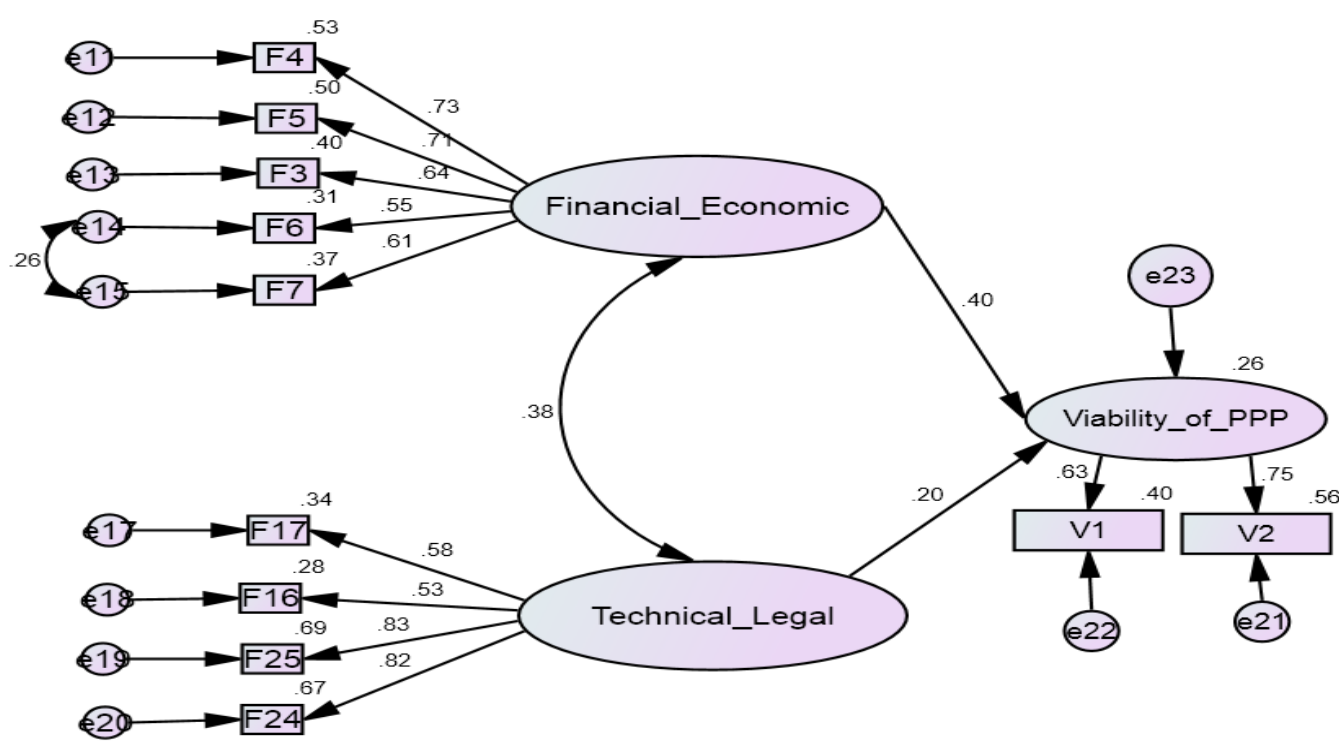

Figure 5. Standardized SEM model for Private sector

Source: Author's result

\subsection{Discussion}

This research conducted a survey to explore the perceptions of PPP stakeholders on factors influencing the feasibility of PPP projects during their life cycle in Vietnam, through the method of structural equation modeling. The research result demonstrated that financial performance \& economic environment and technical sophistication\& legal environment contributed to the viability of PPP road projects in Vietnam. One possible explanation as to why the two factor groups became more important to be considered as improving the viability of Vietnamese PPP projects may be due to the context of PPP projects in Vietnam. Firstly, in fact, application of modern technology to construct and operate PPP road projects is still severely limited. Some contractors still use traditional technology, which has adversely affected the projects in terms of scale and efficiency. Li et al. (2005) advocates, technical aspects are normally one of the most significant considerations in study of project viability. When considering PPP procurement options, it is important to review the associated technical problems. In addition, although PPP has been implemented in Vietnam for two decades, regulations on PPP scheme is still unclear and inconsistent. Such ambiguity has caused certain difficulties for private sector in investing in projects in Vietnam. Therefore, besides technical feasibilities, legal factors are of equal importance in enhancing the viability of PPP. An improved legal framework will significantly boost the feasibility of PPP projects. The consistency of institutional arrangements could maintain a healthier working environment for PPP, increasing transparency while mitigating corruption. Secondly, there are several PPP projects having relatively small capital, whose revenue from solely collecting toll fees is unable to cover the expenditure. As a result, shortly after coming in operation, the consortiums of the projects fail to meet the capital demand to carry out projects.

It should also be mentioned that in the SEM model, we used latent variables to quantify the effects of factors on the feasibility of PPP projects in Vietnam. These variables were not measured directly, instead, computed indirectly through observed variables based on the survey of BOT/PPP stakeholders. "Why would we want to use a latent variable that we did not measure instead of the exact data the 
respondents provide? Although this may sound like a nonsensical or "black box" approach, it has both practical and theoretical justification by improving statistical estimation, better representing theoretical concepts, and accounting for measurement error"(Hair et al. 2010, p.635).

\section{CONCLUSION}

In recent years, public-private partnership has been considered as a key alternative to conventional approaches of developing new Vietnamese projects in road sector due to the limitation of stage budget. However, the viability of PPP road projects of Vietnam is relatively poor when compared with other developing nations. Enhancing the viability of PPP projects is, therefore, essential in developing road systems in Vietnam. The research provides empirical evidence for public policy makers as well as private sector in boosting the viability of PPP in Vietnam. In order to improve the easiness of PPP projects in road sector, public and private partners should take into account the financial performance \& economic environment and technical sophistication\& legal environment. Paying particular attention to "financial interest to private sector", "the profitability of projects", "governmental economic policy" and "long-term demand of service", which are associated with economic \& financial abilities. Regarding technical sophistication\& legal environment, priority should be given to, "service quality" and "flexibility of contracts to change in output", "align with current statutory" and "favorable legal framework".

In terms of theoretical implications, this research makes an academic contribution by quantifying the effect of non-monetary factors on the viability of PPP as well as a quantitative investigation of the difference in perspective between public sector and private sector on factors improving the viability of PPP.

The potential drawback of the research is that using questionnaire as the instrument to determine factors improving the viability of PPP projects, in general, is not a good approach for an individual basis. Another limitation of this study is the absence of individual solution in improving viability of a given PPP project. Alternatively, the research applied SEM to investigate the factors influence the viability of PPP road projects in Vietnam. However, the sample size $(n=201)$ in the research is not large enough to be utilized for multi group analysis of SEM. For example, there were 54 respondents from public sector taking part in the survey, which makes multiple group analysis less persuasive. Researchers should expand more in sample size as well as collecting more opinions from public sector. To assess qualitative VFM for a PPP project in particular, future researches may apply Analytic Hierarchy Process. It is also recommended that future studies should conduct in-depth interview with PPP experts.

\section{ACKNOWLEDGEMENT}

This research has not been received any funding support from any organization.

\section{REFERENCES}

Alfen, H., Kalidindi, S., Ogunlana, S., Wang, S., Abednego, M., \& Jungbecker, A. (2009). Public private partnership in Infrastructure development - Case studies from Asia and Europe. Weimar: Bauhaus-Universität Weimar.

Bagozzi, R., Yi., Y., \& Philips, L. (1991). Assessing construct validity in organizational research. Administrative Science Quarterly, 36(3), 421-458.

Blunch, N. J. (2013). Introduction to structural equation modeling using IBM SPSS statistics and AMOS. London: Saga.

Browne, M., \& Cudeck, R. (1993). Alternative ways of assessing model fit. Newbury Park: Sage Publication.

Cheung, E. (2009). Developing a best practice framework for implementing public private partnerships (PPP) in Hong Kong. PhD diss., Queesland University of Technology. 
Cheung, E., \& Chan, A. (2011). Evaluation model for assessing the suitability of Public-Private Partnerships projects. Journal of Management in Engineering, 27(2), 80-89.

Contreras, C. (2014). Value for money: to what extent does discount rate matter. Revista de Economía Aplicada, XXII (66), 93-112.

FIDIC. (2001). Project Financing Sustainable Solutions - Adding V alue through Innovation Re-assessing the priorities. Federation Internationale des Ingenieurs-Conseils. Geneva.

Fornell, C., \& Larcker, C. (1981). Evaluating structural equation models with unobservable variables and measurement error. Journal of marketing research, 18(1), 39-50.

Hair, J., Black, W. B., \& Anderson, R. (2010). Multivariate data analysis (7th ed.). New Jersey: Pearson Prentice Hall.

Hair, J., Black, W. B., \& Anderson, R. (1998). Multivariate data analysis (5th ed.). New Jersey: Pearson Prentice Hall.

Hemming, R. (2006). Public-Private Partnerships, Government Guarantees, and Fiscal Risk. Washington: International Monetary Fund.

HM treasury. (2006). Value for money guidance. London: The Controller of Her Majesty's Stationery office.

Hooper, D., Coughlan, J., \& Mullen, M. (2008). Structural Equation Modelling: Guidelines for Determining Model Fit. The Electronic Journal of Business Research Methods, 6(1), 53-60.

Hox, J., \& Bechger, T. (1998). An introduction to structural equation modeling. Family Science Review, 11, 354-373.

Hu, L., \& Bentler, P. (1999). Cutoff criteria for fit indices in covariance structure analysis: Conventional criteria versus new alternative. Structural Equation Modeling, 6(1), 1-55.

KDI. (2010). Detailed guideline for value for money test for build-transfer-operate (BOT) Public-private partnership (PPP) projects. Korea Development Institute. Public and Private Infrastructure Investment Management Center.

Li, B., Akintoye, A., Edwards, P., \& Hardcastle, C. (2005). Critical success factors for PPP/PFI projects in the UK construction industry. Management \& Economics, 23(5), 459-371.

NAO . (2013). Review of the value for money assessment process for PFI. Retrieved February 15, 2016, from National Audit Office www.nao.org.uk/wpcontent/uploads/2014/01/Review-of-VFM-assessmentprocessfor-PFI1.pdf

Osei-Kyei, R., \& Chan, A. (2015). Review of studies on the critical success factors for Public-Private Partnership (PPP) projects from 1990 to 2013. International Journal of Project Management, 33(6), 1335-1346.

Ozdoganm, I., \& Birgonul, M. (2000). A decision support framework for project sponsors in the planning stage of build-operate-transfer (BOT) projects. Construction Management and Economics, 18, 343-353.

Park, J. H. (2014). Transport PPP Decisions in Korea: Value for Money Assessment and Risk Quantification. PhD diss., University of Southampton.

Thomas, S. N., Wong, Y. M., \& Wong, M. (2010, May). A structural equation model of feasibility evaluation and project success for public-private partnerships in Hong Kong. IEE Transactions on Engineering Management, 57(2), 310-322.

Tiong, R. (1996). CSFs in competitive tendering and negotiation model for BOT projects. Journal of construction engineering and management, 122(3), 205-211.

Tucker, L.R., \& Lewis, C. (1973). A reliability coefficient for maximum likelihood factor analysis. Psychometrika, 38, 110.

Vietnamese Ministry of Transport. (2016, June 7). Mobilize capital of 186660 billion VNDs to invest PPP projects. Retrieved June 12, 2016, from Vietnamese Ministry of Transport http://www.tapchigiaothong.vn/bo-gtvthuy-dong-186660-ty-dong-dau-tu-du-an-ppp-trong-5-nam-d26977.html

Wong, K. (2013). Partial Least Squares Structural Equation Modeling (PLS-SEM) Techniques Using SmartPLS. Marketing Bulletin, 24(1), 1-32.

Wong, M. W. (2006). Satisfying all stakeholders in evaluating the feasibility of public-private partnership projects: a structural equation model approach. Hong Kong: Department of Civil Engineering. The University of Hong Kong. 
World Bank. (2013). Value-for-Money Analysis Practices and Challenges: How Governments Choose When to Use PPP to Deliver Public Infrastructure and Services. Retrieved March 15, 2016 from World Bank Global Round-Table http://www.ppiaf.org/sites/ppiaf.org/files/publication/VFM.pdf

World Bank. (2015). Private Participation in Infrastructure Database. Retrieved June 16, 2016 from http://ppi.worldbank.org/snapshots/sector/toll-roads

Zhang, X. (2005). Critical Success Factors for Public-Private Partnerships in Infrastructure Development. Journal of Construction Engineering and Management, 131(1), 3-14.

Zhang, X. (2006). Factor analysis of public clients' best-value objective in public-privately partnered infrastructure projects. Journal of construction engineering and management, 132(9), 956-965. 